\title{
Structural Requirements for the Space Propulsion Engine Systems
}

\author{
Pravin K. Aggarwal* \\ NASA Marshall Space Flight Center, Huntsville, AL
}

In January 2004, the National Aeronautics and Space Administration (NASA) was given a vision for Space Exploration by President Bush, setting our sight on a bold new path to go back to the Moon, then to Mars and beyond. As NASA gets ready to meet the vision set by President Bush, failures are not an option. Reliability of the propulsion engine systems will play an important role in establishing an overall safe and reliable operation of these new space systems. A new standard, NASA-STD-5012, Strength and Life Assessment for Space Propulsion System Engines, has been developed to provide structural requirements for assessment of the propulsion systems engine. This standard is a complement to the current NASA-wide standard NASA-STD-5001, Structural Design and Test Factors of Safety for Spaceflight Hardware, which excluded the requirement for the engine systems (rotatory structures) along with pressure vessels. As developed, this document builds on the heritage of the multiple industrial standards related to strength and life assessment of the structures. For assuring a safe and reliable operation of a product and/or mission, establishing a set of structural assessment requirements is a key ingredient. Hence, a concentrated effort was made to improve the requirements where there are known lessons learned during the design, test, and operation phases of the Space Shuttle Main Engine (SSME) and other engine development programs. Requirements delineated in this standard are also applicable for the reusable and/or human missions. It shall be noted that "reliability of a system cannot be tested and inspected but can only be achieved if it is first designed into a system." Hence, these strength and life assessment requirements for the space propulsion system engines shall be used along with other good engineering practices, requirements, and policies.

\section{Introduction}

NASA has a very well-defined program and process to develop a set of standards for use in design, development, and certification of flight hardware. This was necessitated to provide uniformity across NASA centers and in response to the federal law ${ }^{1}$ which requires the use of industry standards, where available.

In response to this standard's development activity, a new standard for Structural Strength Requirement, NASASTD-5001 $1^{2}$, was developed and released. Since the release of this standard, all new programs have been using this standard as the first choice for designing new spacecraft and vehicles. However, at the release of this document, rotatary hardware (engines) and pressure vessels were not included in the scope of this document.

As we initiated new propulsion system engine development programs, since the commencement of the new standard, NASA-STD-5001, it was noticed that no NASA-wide standard and/or industry standard is available which outlines the Strength and Life Assessment Requirements for the Space Propulsion System Engines. Although a historical standard, Marshall Space Flight Center's MSFC-HDBK- $505^{3}$ could still be used. It was also realized that there are some requirements which need to be enhanced based upon the lessons learned. MSFC-HDBK-505 (and as modified by the Prime contractor and accepted per Contract End Item) was primarily used as a basis for the design of the SSME. Hence, a request was made and accepted by the NASA Technical Standards Program to develop a dedicated Strength and Life Assessment Requirements for the Space Propulsion System Engines.

\footnotetext{
" AIAA Member, Division Chief - Structural Design and Analysis Division/EV30, NASA/MSFC
} 


\section{Procedure}

Design of high-performance engines for space application requires an interaction of multiple inputs as shown in Figure 1. A good criteria plays a strong role since operating environments are very harsh (extreme cryogenic or high temperatures, high pressures, propellant/material interaction), and there is a need for keeping the low weight for maximum payload capacity, etc.

While developing this standard, the developer took special care to assure that criteria should be concise and based upon good engineering judgment (since, a criterion for primary application in space industry should not constrain innovation and stifle creativity.) A balance is required to assure reliable mission operation yet be lightweight and affordable. Also:

a. Regardless of popular belief, engineers are human beings; we are prone to make errors. Hence we need design margins to guard against the errors.

b. Objective of the good "structural assessment" is to predict success, not failures.

c. Engine/Component reliability cannot be analyzed in, it must be designed in.

Hence, this new standard was developed with the following as its basis:

1. Use historical requirements, where possible

2. Incorporate lessons learned, where applicable

3. Adopt/refer to non-Government voluntary standard (industry) where available and applicable

As proposed, this standard provides strength and life assessment requirements for all NASA space propulsion system engines. Life, as used in this standard, refers to fatigue and creep. In addition, test requirements for qualification and verification assessment are specified

\section{Strength Criteria}

Design safety factors are intended, as listed in popular textbooks, to cover for:

a. To allow for accidental overloading of structure, as well as for possible inaccuracies in the construction and possible unknown variables in analysis of the structure.

b. Although not commonly used, perhaps a better term for this ratio is factor of ignorance.

c. A factor of safety is used in the design of structures to allow for (1) uncertainty of loading, (2) the statistical variation of material strengths, (3) inaccuracies in geometry and theory, and (4) the grave consequence of failure of structures

Hence, a set of factor of safety are defined. These requirements are mostly based upon the historical requirements currently being used and are expressed by reference to other standards. Currently, factor of safety requirements are verified using the primary stresses/strains which do not account for secondary stresses/strains (e.g., thermal and/or misalignments). Hence, a new requirement for strain to crack initiation margin is being proposed for total loads. Having a factor safety requirement for total strain will guard against a design which may result in strain to crack initiation. In addition, it is recognized that for some applications, it may be appropriate and necessary to use additional design factors such as fitting factors, casting factors, impact factors, etc., in conjunction with the factors of safety specified in Table 1. For example:

a. Brazed, welded, and bonded joints require other special factors consistent with their processing and criticality, but shall be at least as severe as those in Table 1 .

b. Margins of safety on performance-driven clearances (for example, in turbo machinery) are generally calculated using a safety factor of one. Margins of safety in situations intended to prevent impact, such as an engine fully gimbaled, shall use a safety factor of 1.4 at MDC loads, i.e., the clearance must be zero or positive at $1.4 \mathrm{X}$ MDC loads. 
c. The factors in Table 1 shall be used with well-behaved and well-understood materials. For materials not in this category, additional factors may be required. For example, titanium alloys have been shown to be susceptible to failure near the yield load. For titanium alloys, the maximum peak stress (the total concentrated stress from all sources, i.e., MDC loads) shall be less than 80 percent of the material minimum-yield strength.

\section{Fatigue Criteria}

The requirement established here enhances the requirements in the fatigue analysis area. It shall be recognized that the propulsion system is a critical element of the spacecraft system and has been found to be the primary cause of failure ${ }^{5}$ (Figure 2).

During the initial design of the SSME, a Fatigue Analysis Factor (FAF) of 1.0 and a Service Life Factor (SLF) of 4.0 was used. In certain cases, where high-cycle fatigue properties were based upon limited or no data, a SLF of 10 was used. This resulted in extensive repair, inspection and hardware refurbishment to guard against operationrelated fatigue cracking noted during the ground test program, and post-flight inspection. Subsequently, as high pressure turbopumps were redesigned, fatigue criteria were revised to use a FAF of 1.15 and SLF of 10.0. This criterion resulted in a reduced rate of fatigue-related cracking. It is interesting to note that SSME prime contractor, Rocketdyne, also realized that fatigue-related criteria needed an enhancement and proposed that for redesign of SSME components, a minimum of 500 cycles with a FAF of 1.5 for low-cycle fatigue and a factor of 1.0 on endurance with a FAF of 1.25 , or equivalent alternate stress, for high-cycle fatigue shall be used as a good design practice $^{6}$.

Similarly, for the Space Transportation Main Engine ${ }^{7}$ program a SLF of 10 was proposed to guard against low and high-cycle fatigue cracking along with a FAF of 1.15 in 1992 . Hence, during the write-up of the proposed requirements, a balance was made to strengthen the criteria for rotatory parts of the engines where failures are less forgiving and maintain the current requirements for the stationary components but use the service life factor of 10.0 to reduce the potential of fatigue-related cracking and assure it does not result in weight penalty.

Hence it is proposed that all structural elements shall be designed and analyzed to demonstrate the following factors:

(1) A FAF shall be multiplied by the limit stress/strain prior to entering the S-N design curve to determine the low-cycle/high-cycle life. The FAF shall be:

$$
\begin{aligned}
& \text { FAF }=1.25 \text { Rotating components } \\
& \text { FAF }=1.15 \text { Non-rotating components }
\end{aligned}
$$

(2) Service Life Factor. The low-cycle factor (LCF) and high-cycle factor (HCF) analyses shall demonstrate a minimum calculated life of 10.0 times the service life.

\section{Test Verification}

Based upon the experience gained during the SSME test verification process and weibayes statistical analysis, it is recommended that at least six units be tested for extended duration to assure the reliability of the mission. (Figure 3 )

For multiple units/multiple use propulsion systems, the following criteria needs to be considered in order to establish test program requirements:

a. Reliability for initial mission use requires minimum amount of testing regardless of mission-life requirements

b. Basic material/load scatter, difficulty in measuring localized strains

- Reliability for continued engine use requires sustained ground testing

- Multiple units at or near fleet leader are required 


\section{Summary}

The purpose of the proposed standard is to provide a consistent set of requirements in the design and assessment of space propulsion system engines. As we design/develop new engine systems which use the philosophy of minimum-risk. These enhanced requirements should help alleviate the fatigue-related cracking, improve reliability, and reduce the redesign and maintenance cost. These requirements are intended to provide strength and life criteria in conjunction with other good engineering practices; e.g., attention to details while designing the stress concentration areas to avoid sharp radii, specifying appropriate surface finish. Hence, these strength and life assessment requirements for the space propulsion system engines shall be used along with other good engineering practices, requirements, and policies.

\section{Acknowledgements}

The author is indebted to Mr. Gwyn Faile for guiding, mentoring, and developing the criteria; and to his colleagues across the other NASA centers in reviewing and providing constructive comments. The author is also appreciative of the NASA Technical Standards Program office for funding the development of this standard. Additionally, author also acknowledges that some material presented here was adopted from miscellaneous presentations prepared by other present and past NASA colleagues.

\section{References}

1. OMB Circular A-119: Federal Participation in the Development and Use of Voluntary Consensus Standards and in Conformity Assessment

2. NASA-STD-5001: Structural Design and Test Factors of Safety for Spaceflight Hardware

3. MSFC-HDBK-505, Structural Strength Program Requirements

4. NASA-STD-5012 (draft): Strength and Life Assessment Requirements for Space Propulsion System Engines

5 NASA-Pub8-1086, adopted from Launch Space magazine article written by Charles Gunn (January 1999)

6. Rocketdyne Memo: Structural Analysis Procedures: SSME Redesign Guidelines

7. MSFC-HDBK-1997: Space Transportation Main Engine Structural Strength and Life Program Requirements 
AIAA-2004-xxxx

Figure 1
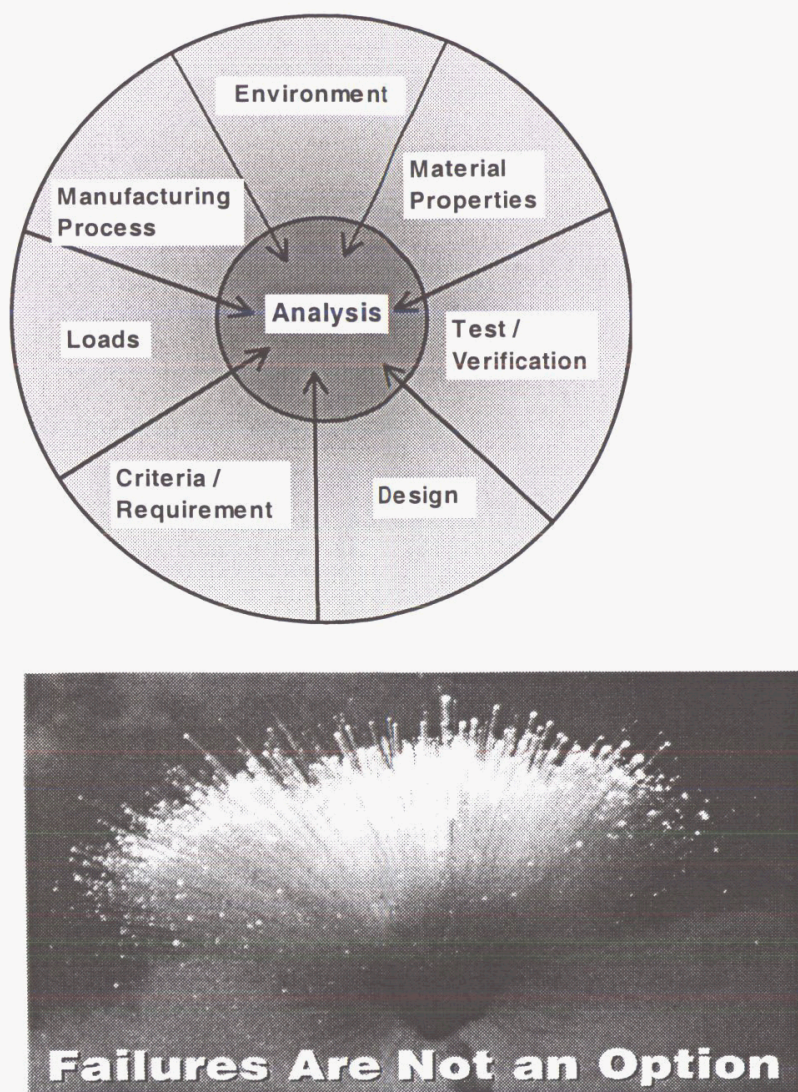

Figure 2

\section{Lessons Learned}

External, independent review teams judging the flight readiness of a vehicle should keep in mind the following key lessons gleaned from the past 20 years of space launches:

1. Propulsion systems are the primary cause of all launch failures. All propulsion test and checkout anomalies/failures demand special attention and review.

2. Hardware built out of normal sequence and hardware that has been reworked are major causes of failures. The processes, procedures. quality inspections, and particularly the re-test qually inspections, and particu

3. There are no small, inconsequential changes in flight-critical components or subsystems. Systems engineering and every affected technical discipline must be involved in the assessment of all new systems and their changes. If a change is not recertified by test, the rationale must be thoroughly examined.
4. Test results that are "in-family," but near the edge of the acceptable envelope, should be thoroughly examined. Usually there is a subtle message. Always believe test data until they are conclusively proved wrong beyond all doubt.

5. All test anomalies/failures must be thoroughly understood and convincingly explained. All hardware that is potentially related to an unverified system anomaly/failure must be purged from the system before launch.

6. The flight environments and dynamic loads that set the qualification and acceptance test levels of each flight-critical component must be rigorously validated by a continuum of flight measurements and analyses.
$\%$ Reliability with $95 \%$ confidence

(Assumption: Weibays distribution,

no failure)

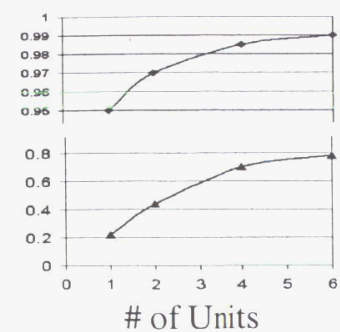

Figure 3
First mission of 500 seconds assuming each unit has been tested for 30,000 seconds

Mission at or near Fleet leader/2 assuming each unit has been tested at or near Fleet leader 
Table 1-Minimum Analysis Factors Of Safety And Strength Test Factors

\begin{tabular}{|c|c|c|c|c|c|}
\hline \multirow{2}{*}{ Engine Hardware Type } & \multirow{2}{*}{ Load } & \multirow{2}{*}{$\begin{array}{l}\text { Mode of } \\
\text { Failure }\end{array}$} & \multirow{2}{*}{$\begin{array}{l}\text { Analysis } \\
\text { Factor of } \\
\text { Safety }\end{array}$} & \multicolumn{2}{|c|}{ Test Factors $^{2}$} \\
\hline & & & & Qualification & Proof $^{\text {Acceptance/ }}$ \\
\hline $\begin{array}{l}\text { Metallic Structures and Components } \\
\text { Yield } \\
\text { Ultimate } \\
\text { Ultimate } \\
\text { Ultimate-pressure or rotation } \\
\text { Ultimate }\end{array}$ & $\begin{array}{l}\text { mechanical only } \\
\text { mechanical only } \\
\text { MDC } \\
\text { MDP or spin } \\
\text { MDC }\end{array}$ & $\begin{array}{l}\text { net section } \\
\text { net section } \\
\text { stability } \\
\text { net section } \\
\text { point strain }\end{array}$ & $\begin{array}{l}1.10^{4} \\
1.40 \\
1.40 \\
1.50 \\
2.00^{4}\end{array}$ & $\begin{array}{l}\text { NA } \\
1.40 \\
1.40 \\
1.50 \\
1.40\end{array}$ & $\begin{array}{l}\text { NA } \\
\text { NA } \\
1.20 \\
1.20^{5,6} \\
1.20\end{array}$ \\
\hline $\begin{array}{l}\text { Pressurized components } \\
\text { (pressure vessels, lines, fittings, } \\
\text { fluid return sections and hose, } \\
\text { bellows, etc.) }\end{array}$ & $\begin{array}{l}\text { MEOP, MDP, or } \\
\text { MDC as applicable }\end{array}$ & \multicolumn{4}{|c|}{$\begin{array}{c}\text { MIL-STD-1522 or ANSI/AIAA S-080, ANSI/AIAA S-081, } \\
\text { AFSPCMAN } 91-710\end{array}$} \\
\hline $\begin{array}{l}\text { Fasteners and Preloaded Joints } \\
\text { Yield } \\
\text { Ultimate } \\
\text { Joint Separation } \\
\quad \text { - Safety Critical }^{7} \\
\end{array}$ & $\begin{array}{l}\text { MDC } \\
\text { MDC } \\
\text { MDC } \\
\text { MDC }\end{array}$ & $\begin{array}{l}\text { net section } \\
\text { net section } \\
\text { separation } \\
\text { separation } \\
\end{array}$ & $\begin{array}{l}1.10^{4} \\
1.40 \\
1.20 \\
1.40 \\
\end{array}$ & $\begin{array}{l}\text { NA } \\
1.40 \\
1.20 \\
1.40 \\
\end{array}$ & $\begin{array}{l}\text { NA } \\
1.20 \\
1.20 \\
1.20 \\
\end{array}$ \\
\hline $\begin{array}{l}\text { Composite and/or bonded } \\
\text { structures and components - } \\
\text { ultimate strength } \\
\text { Uniform areas } \\
\text { Stress concentration areas } \\
\text { Bonds/joints } \\
\text { Ablatives } \\
\end{array}$ & $\begin{array}{l}\text { MDC } \\
\text { MDC } \\
\text { MDC } \\
\text { MDC }\end{array}$ & $\begin{array}{l}\text { point stress } \\
\text { point stress } \\
\text { point stress } \\
\text { point stress }\end{array}$ & $\begin{array}{l}1.40 \\
2.00 \\
2.00 \\
1.70^{8}\end{array}$ & $\begin{array}{l}1.40 \\
1.40 \\
1.40^{5} \\
1.40^{5,8} \\
\end{array}$ & $\begin{array}{l}1.20^{5} \\
1.20^{5} \\
1.20^{5} \\
1.20^{5} \\
\end{array}$ \\
\hline $\begin{array}{l}\text { Pressure checkout with } \\
\text { pcrsonnel present } \\
\text { Yield } \\
\text { Ultimate } \\
\end{array}$ & $\begin{array}{l}\text { checkout pressure } \\
\text { checkout pressure }\end{array}$ & $\begin{array}{l}\text { Note } 9 \\
\text { Note } 9\end{array}$ & $\begin{array}{l}1.50^{4} \\
2.00\end{array}$ & $\begin{array}{l}\text { NA } \\
\text { NA }\end{array}$ & $\begin{array}{l}\text { NA } \\
\text { NA }\end{array}$ \\
\hline
\end{tabular}

Notes:

1. Margins must be written using the specified analysis factor of safety for all the specified loads and modes of failure.

2. Minimum factors which shall be used in the test program to be defined in the SAP for a specific project.

3. Fracture control may require higher factors if the proof test will be used for flaw screening.

4. For titanium alloys, the maximum peak stress (the total concentrated stress from all sources, i.e., MDC loads) shall be less than 80 percent of the material minimum yield strength.

5. These tests are always required.

6. Test pressure $=\mathrm{MDP} \times 1.20 \times \mathrm{ECF} \geq 1.05 \times \mathrm{MDP}$

Test speed $=\sqrt{ }\left(\right.$ MDC speed $\left.^{2} \times 1.20 \mathrm{ECF}\right) \geq \sqrt{ }\left(\right.$ MDC speed $\left.^{2} \times 1.05\right)$

7. Joints for which separation would be a catastrophic event.

8. Anaiysis and test factors appiy at end of life. Qualification test occurs on a hot-fired (fulily abiated) fiignit-iype test article.

9. Net section for metallic, point stress on ultimate only for composites or adhesive bonds. 


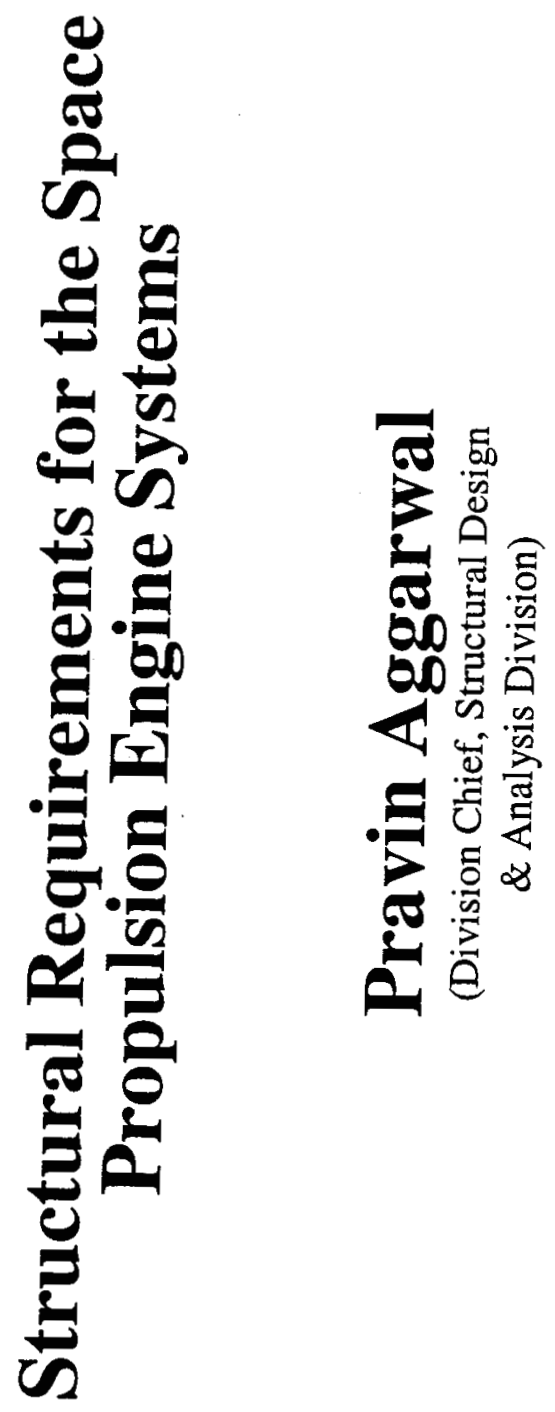




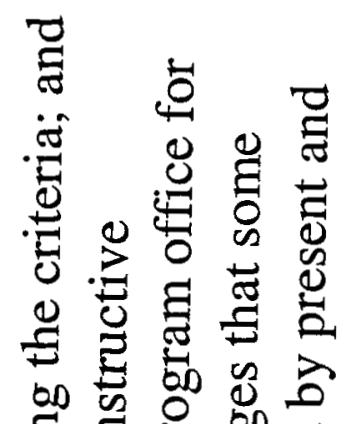

. 둥 융

잉 of $\frac{0}{3}$

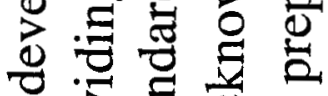

号忢 芯

무유 윰

क 유

프

항 응 응

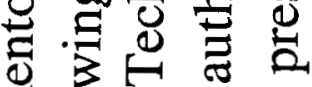

g $0 \ll$

i六

워

可 ¿

为寻

$\rightarrow$ 过

\& 8 :

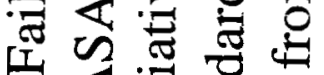

I $4 \cdot \overline{0}$

六Z䒕焉

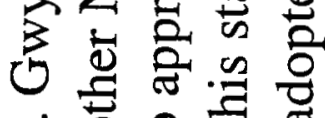

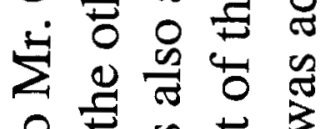

○㱑

导 怘芯

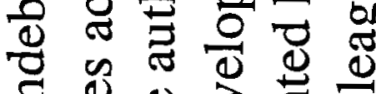

ज

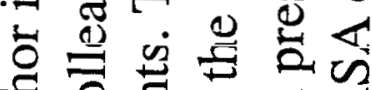

五

元舀 


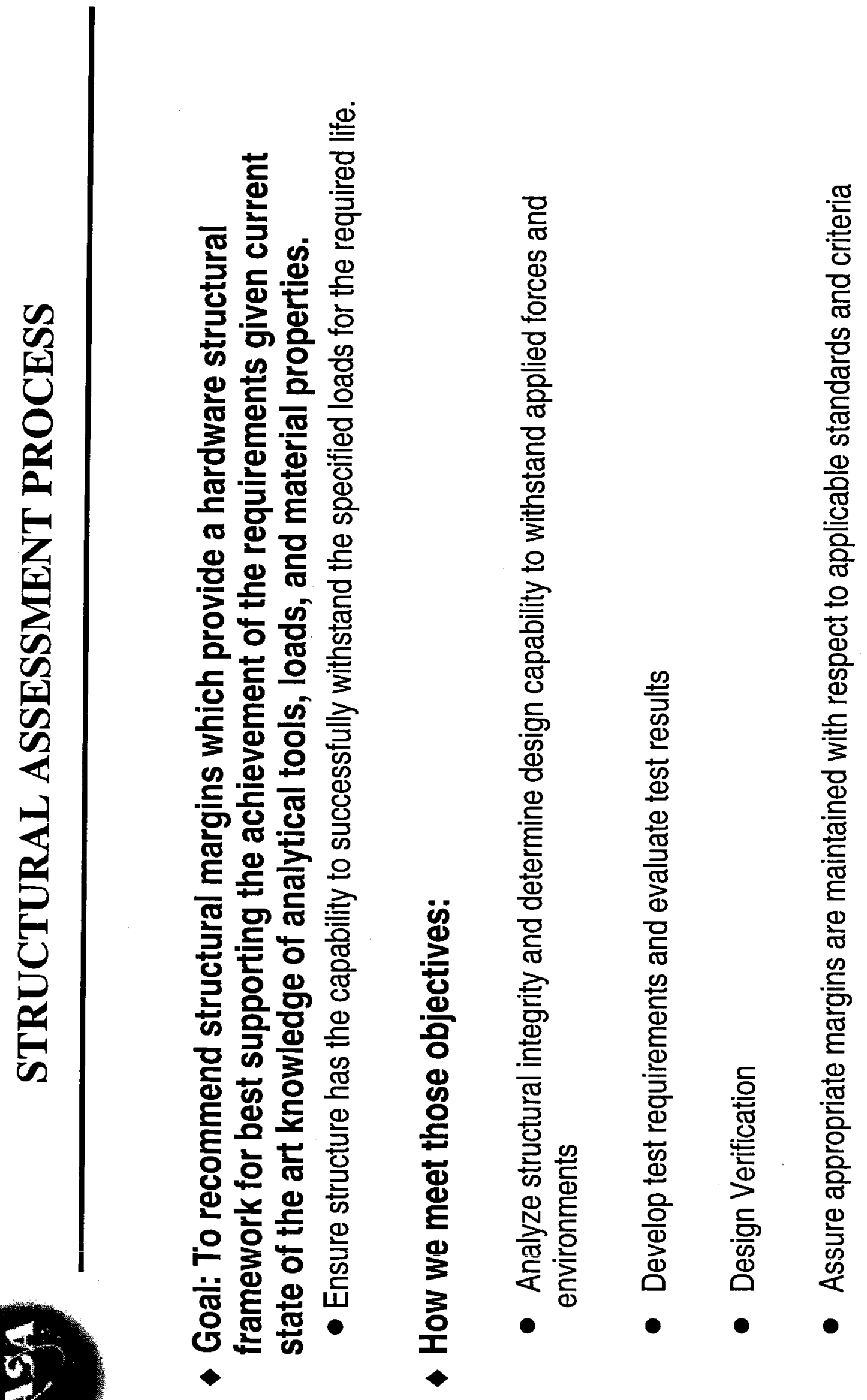




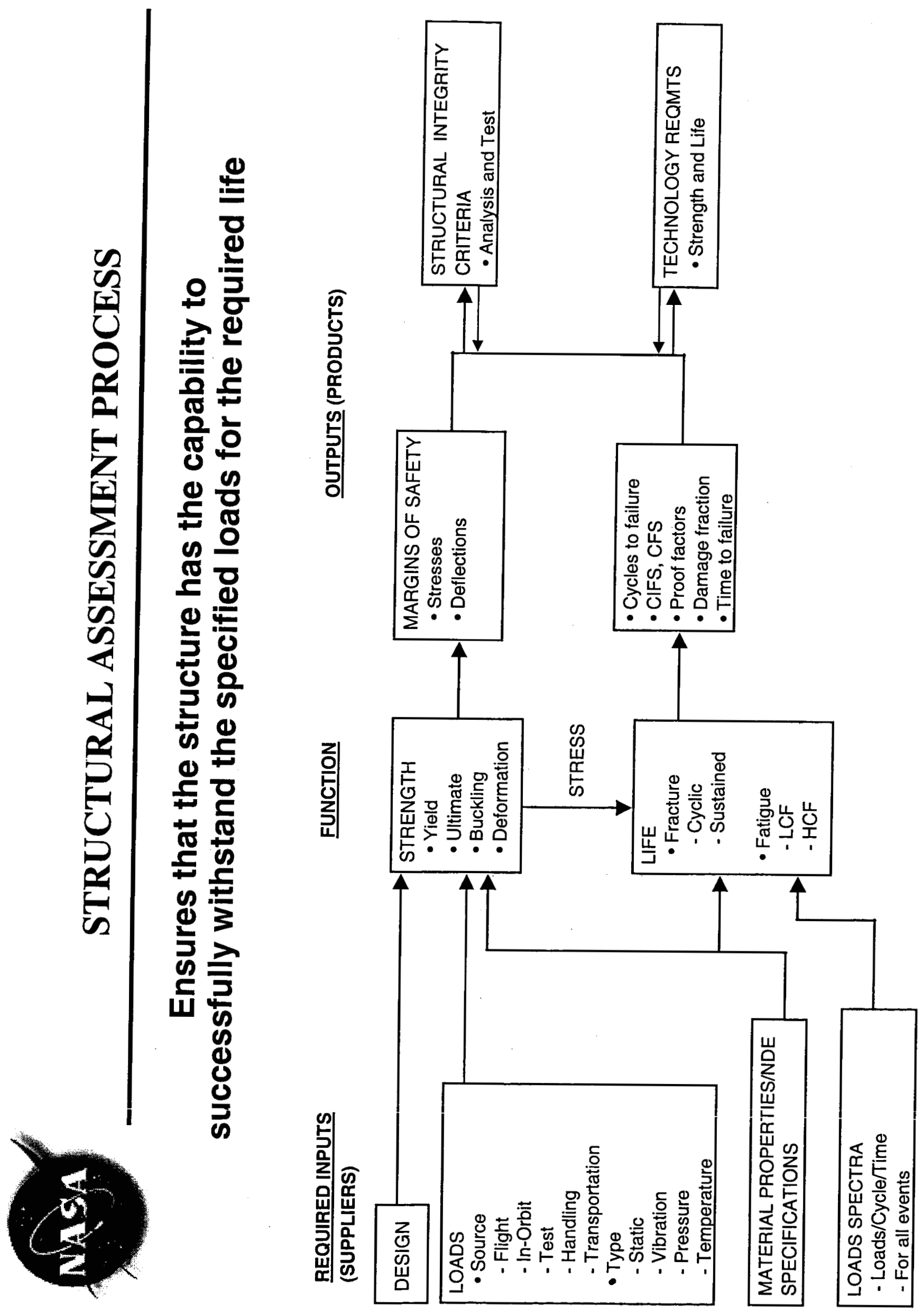




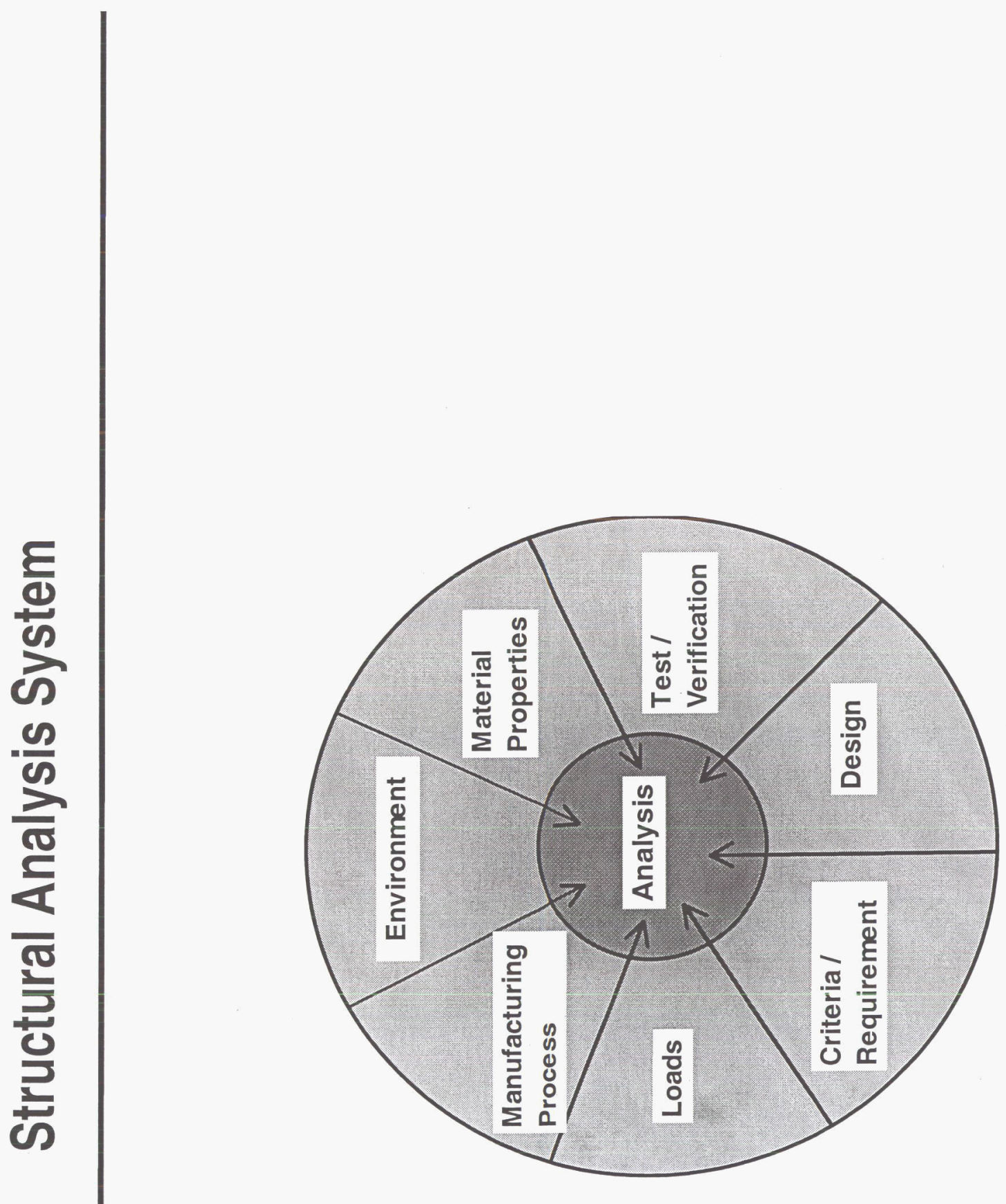




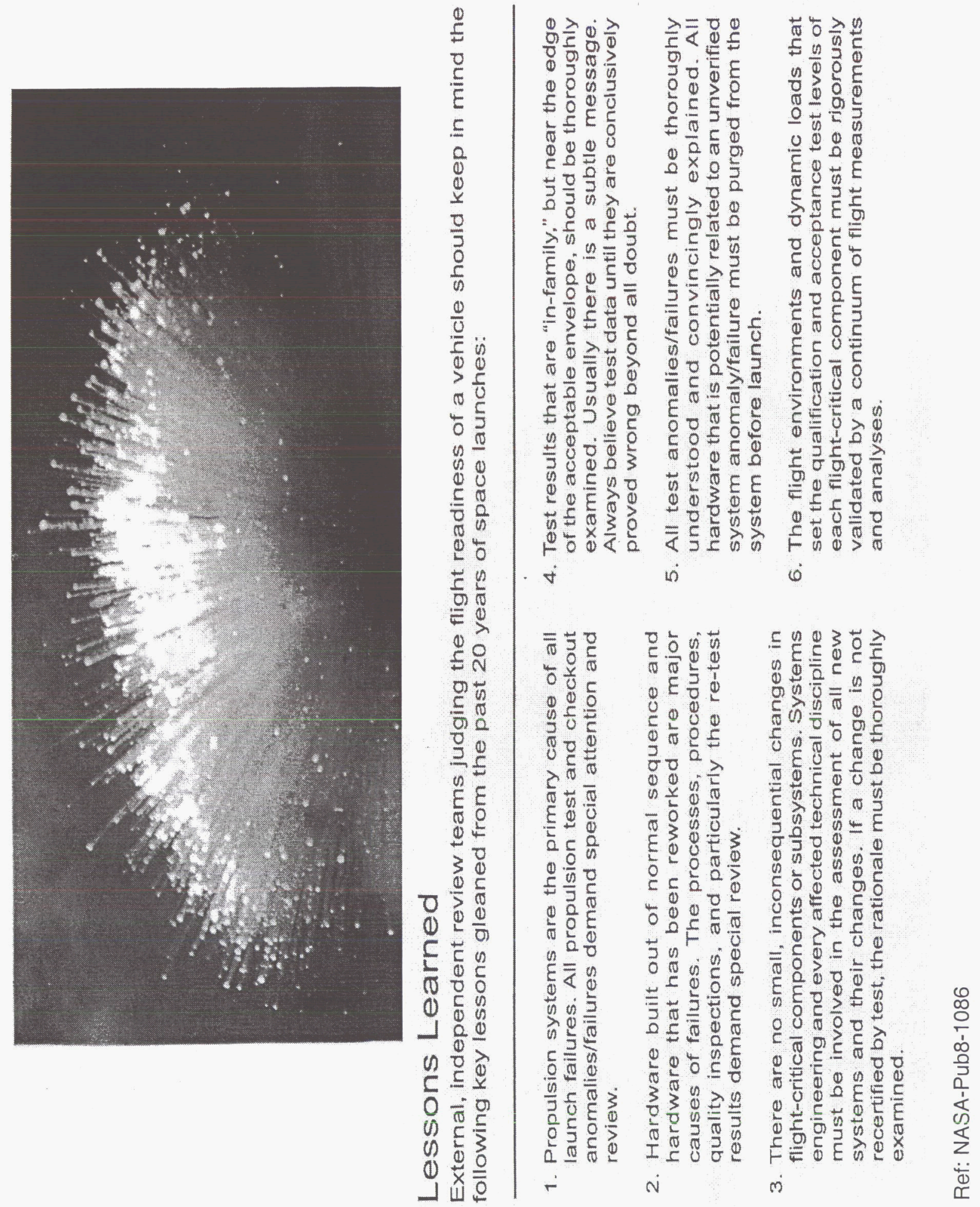




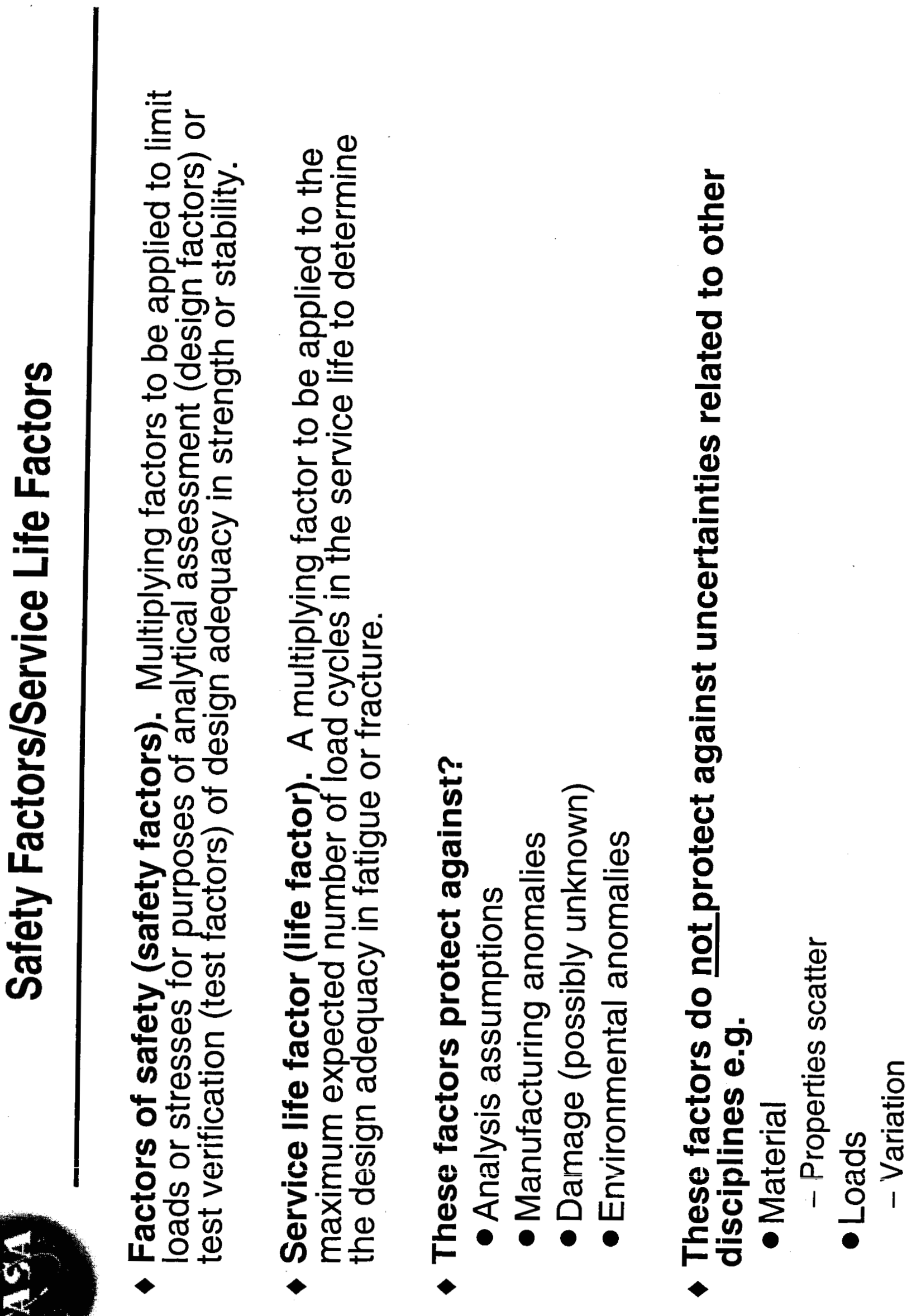




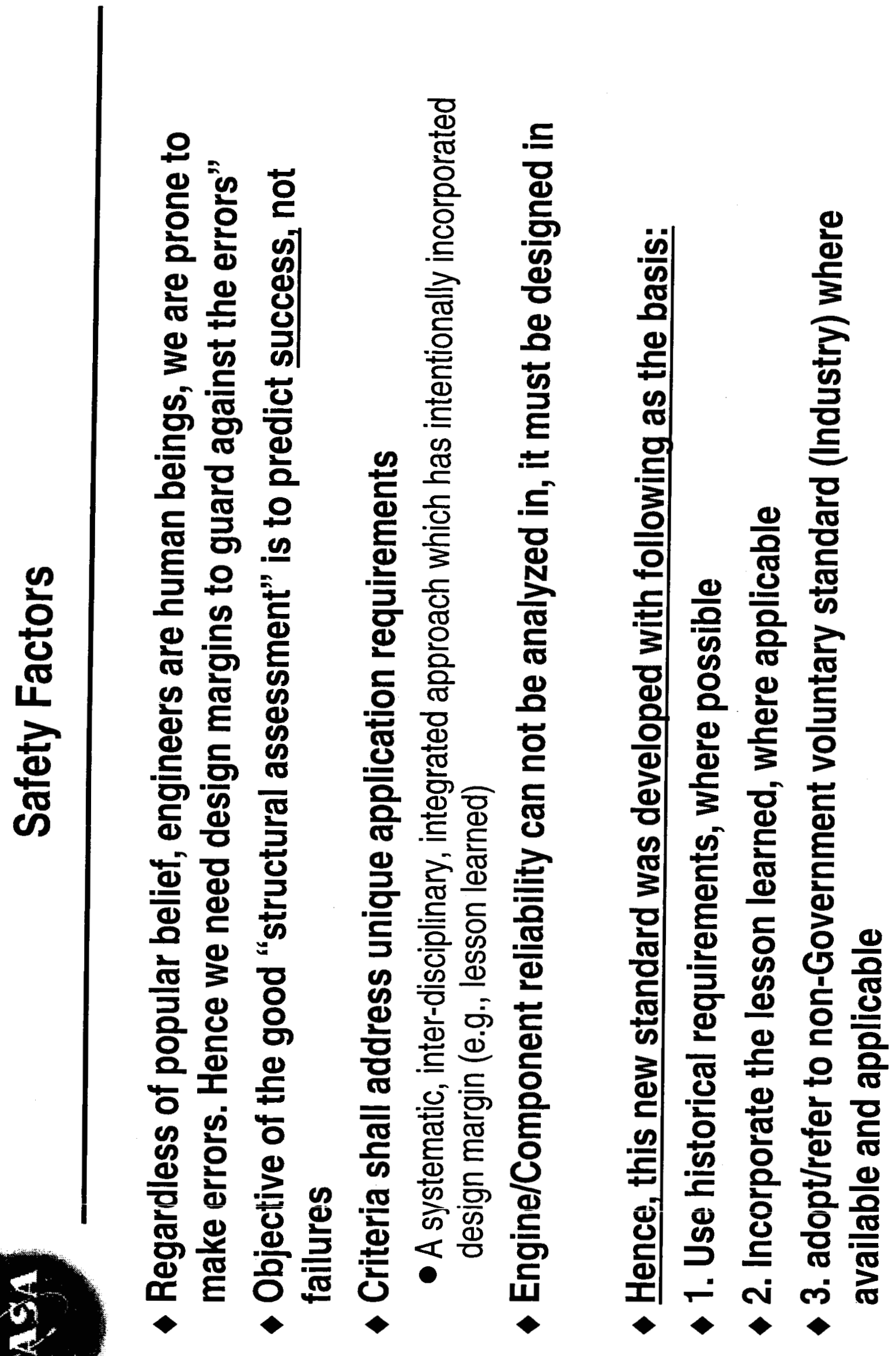




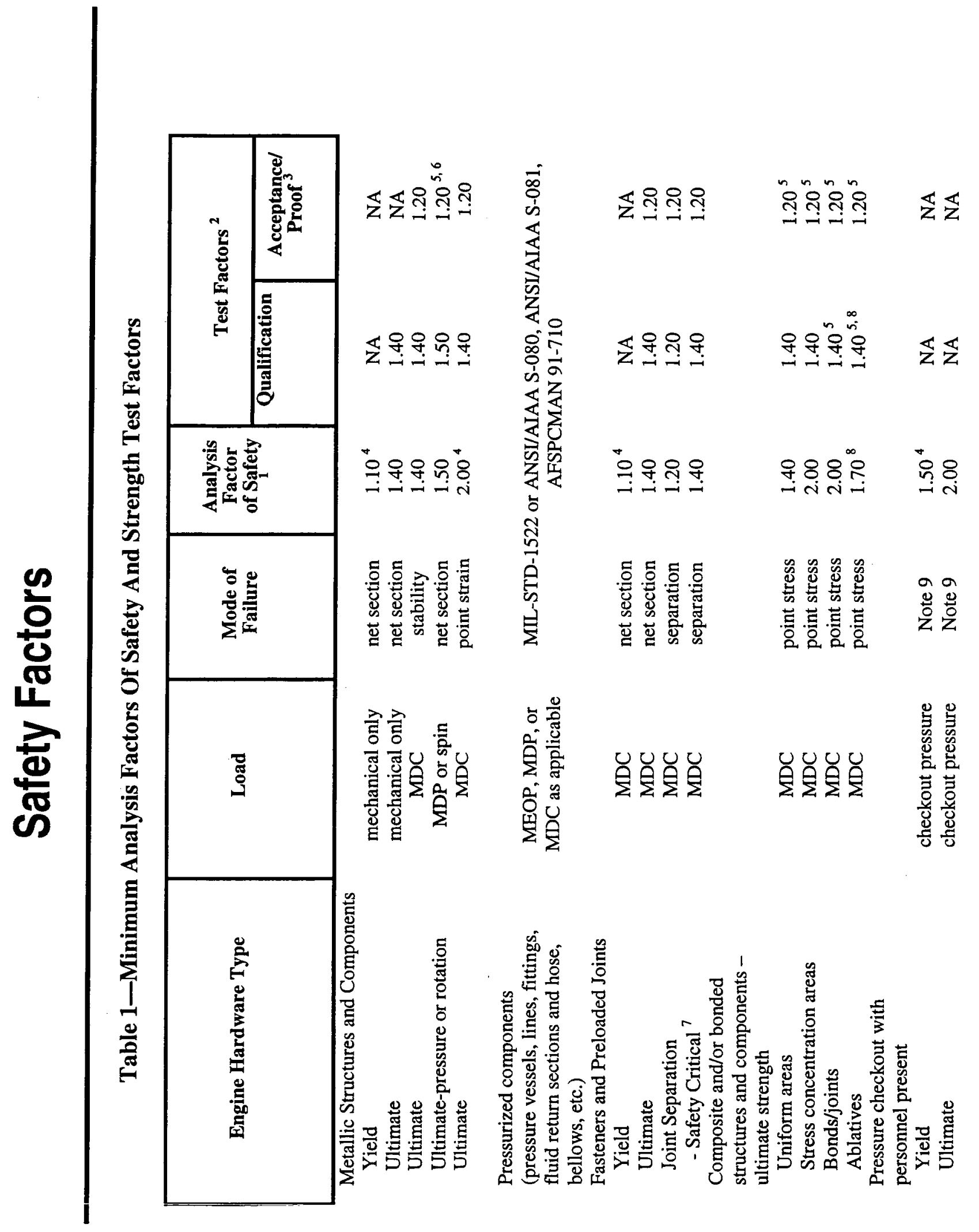




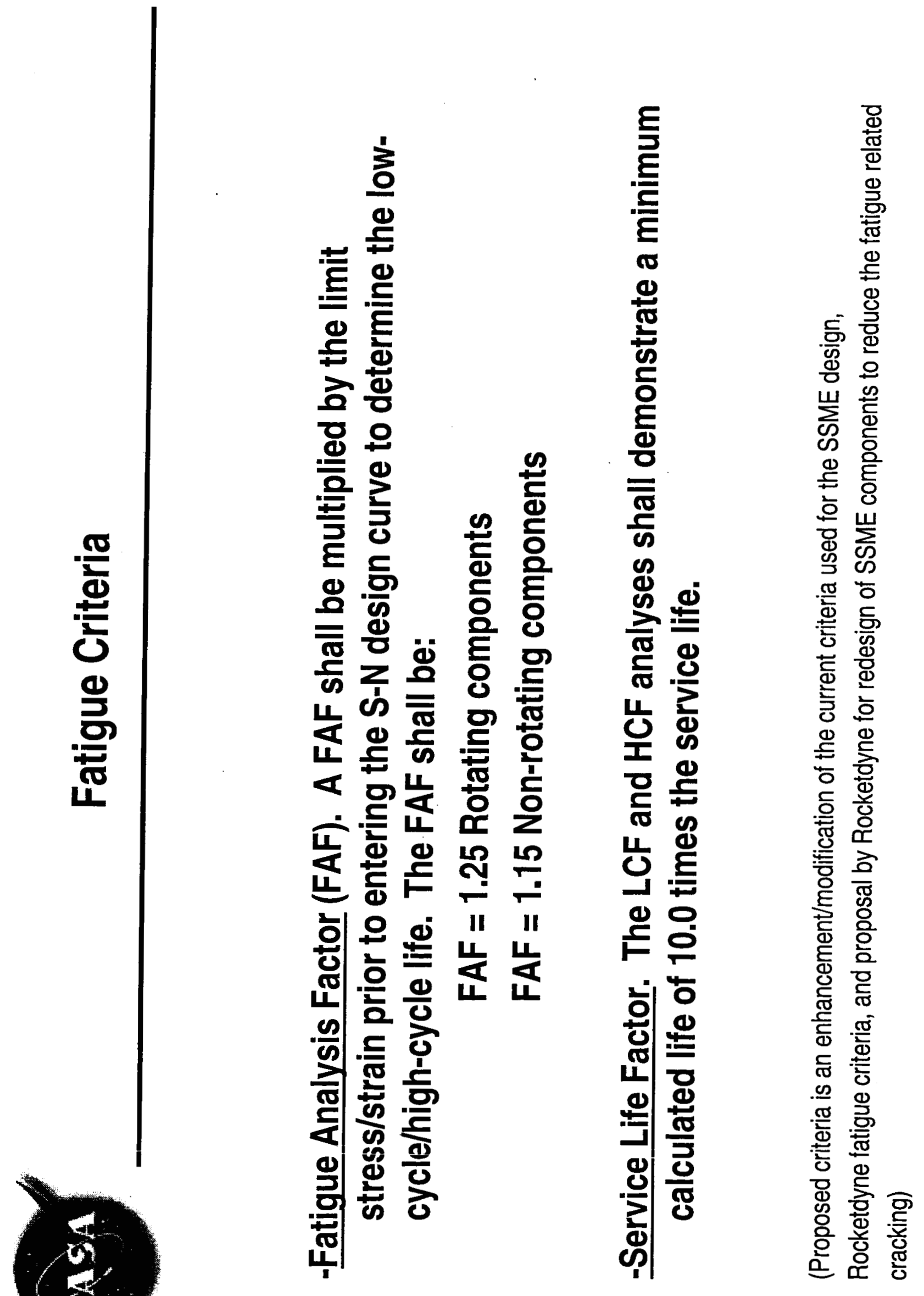




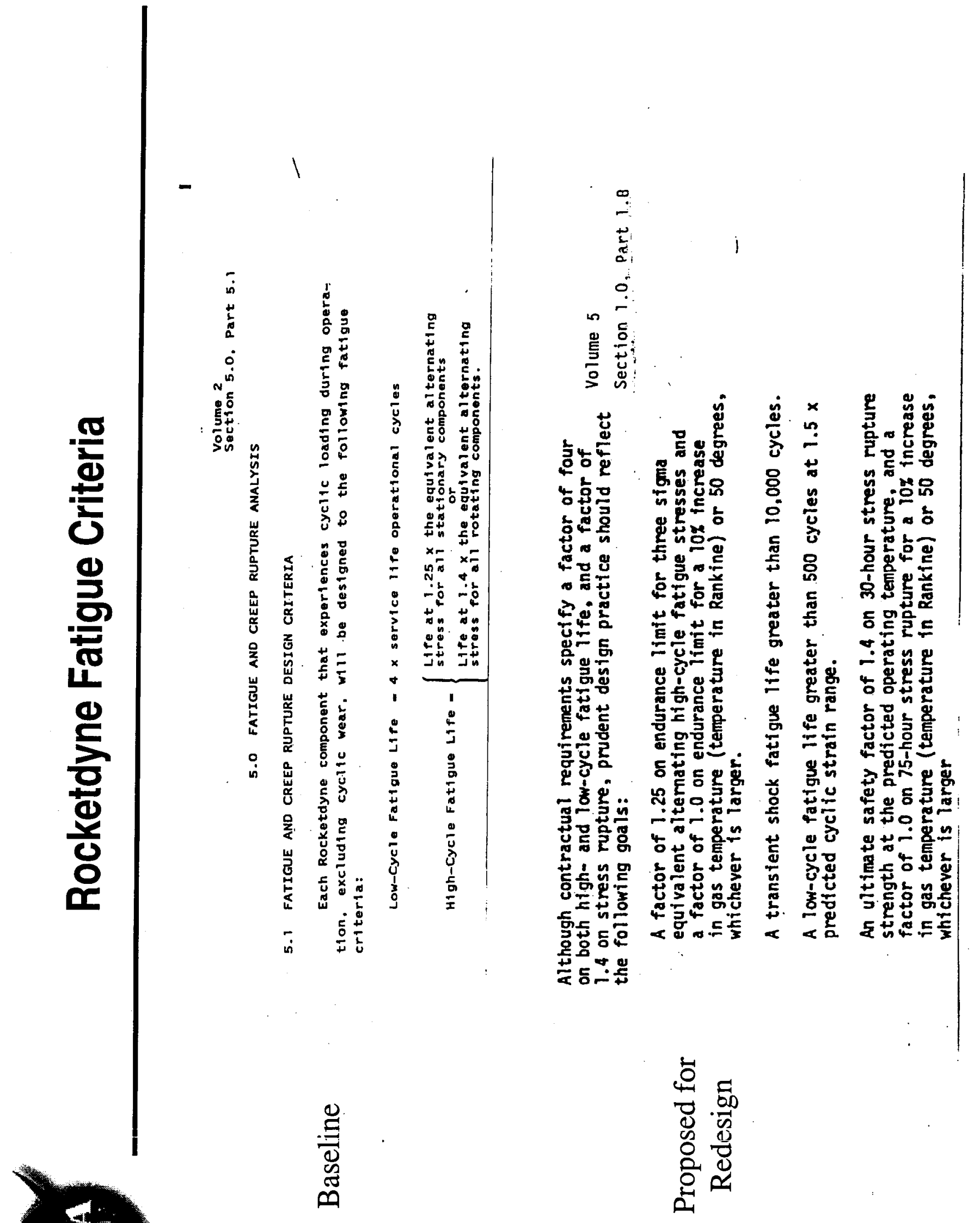


平 $\frac{\omega}{\omega}$

क $\frac{\mathscr{D}}{\Phi} \stackrel{\mathscr{\Phi}}{\Phi}$

'̇ं

동 응

도ㅇㅛㅡㄹ 응

हूㅇํ 응

ง 을

6

\

"

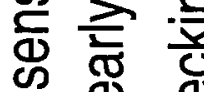

凹

음 음 궁

$\cdot \frac{\pi}{2}$

8

를 을 응

흔 은 은

익 它

$\Phi$

잉 용

क ल क ष

ฮี

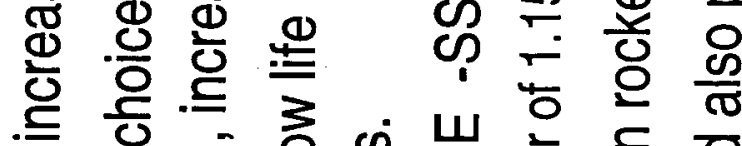

这

$\frac{\tilde{c}}{2}$

응 등 으 흘

$\underbrace{\circ}_{0}$

ᄂ

(1)

(1)

20

(ํ) O

U U 익

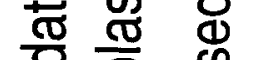

ฮ) त्ष

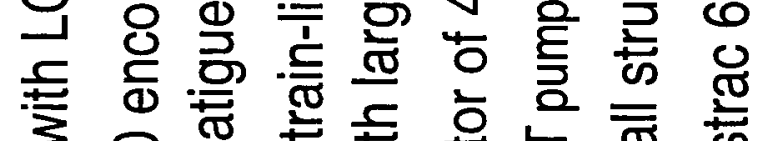

60

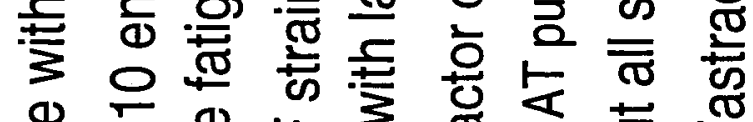

®

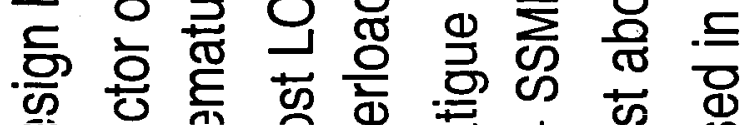

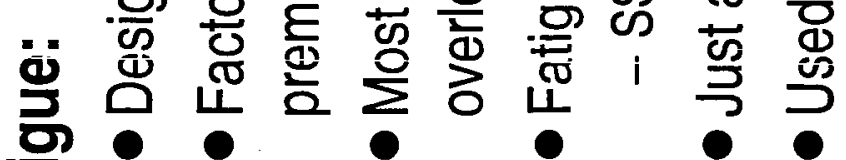

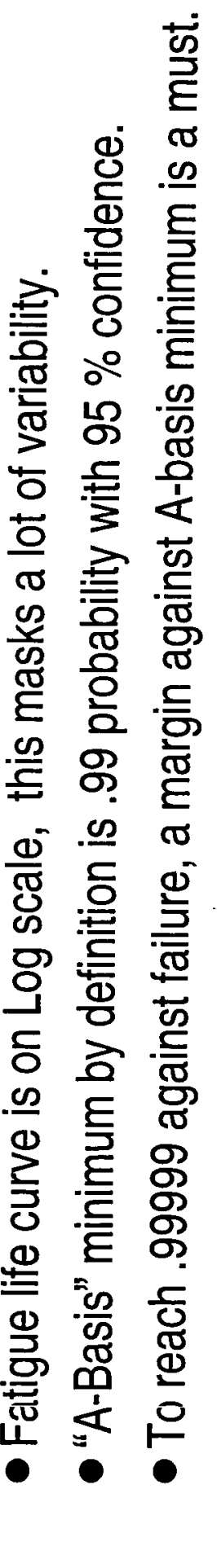




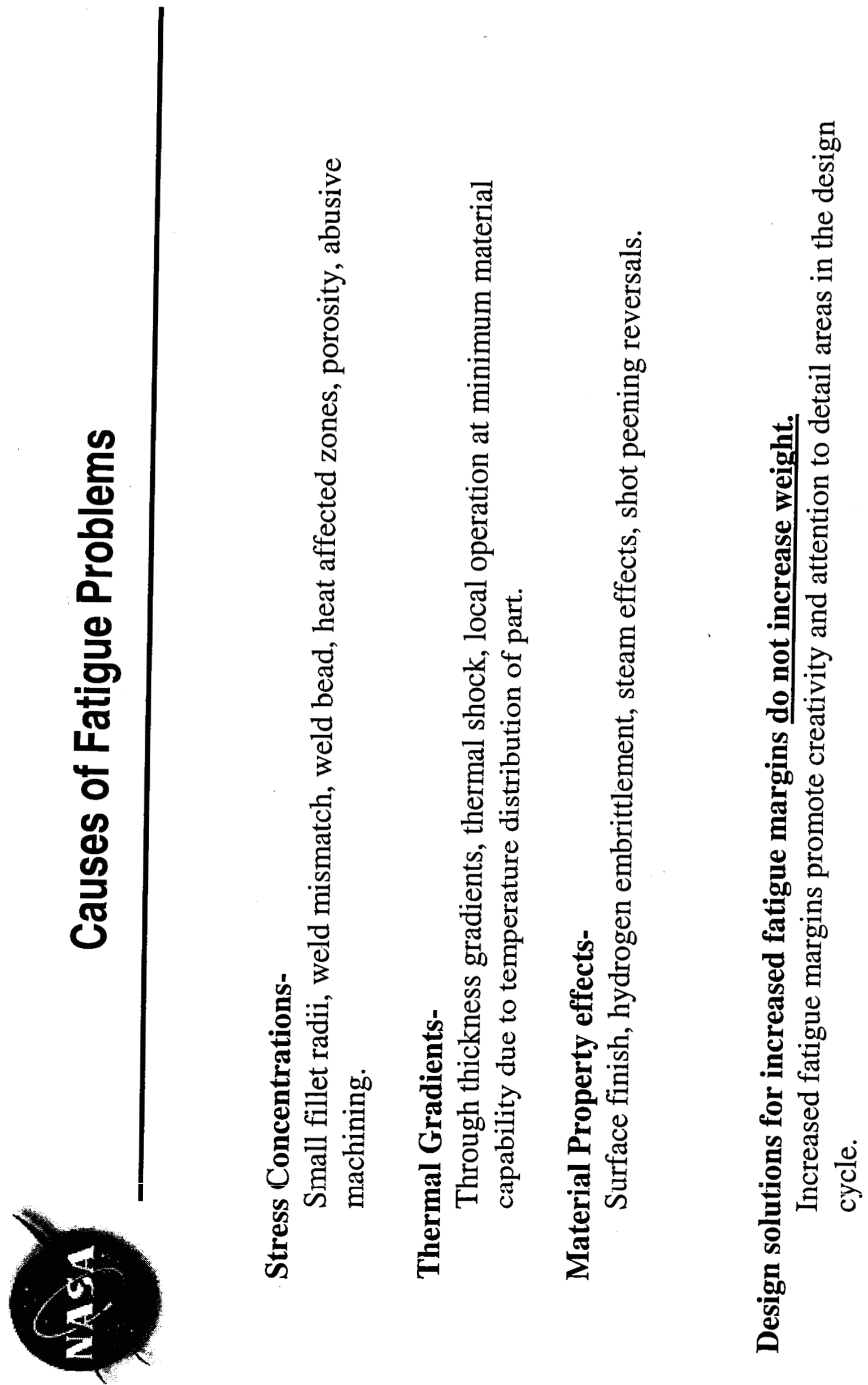




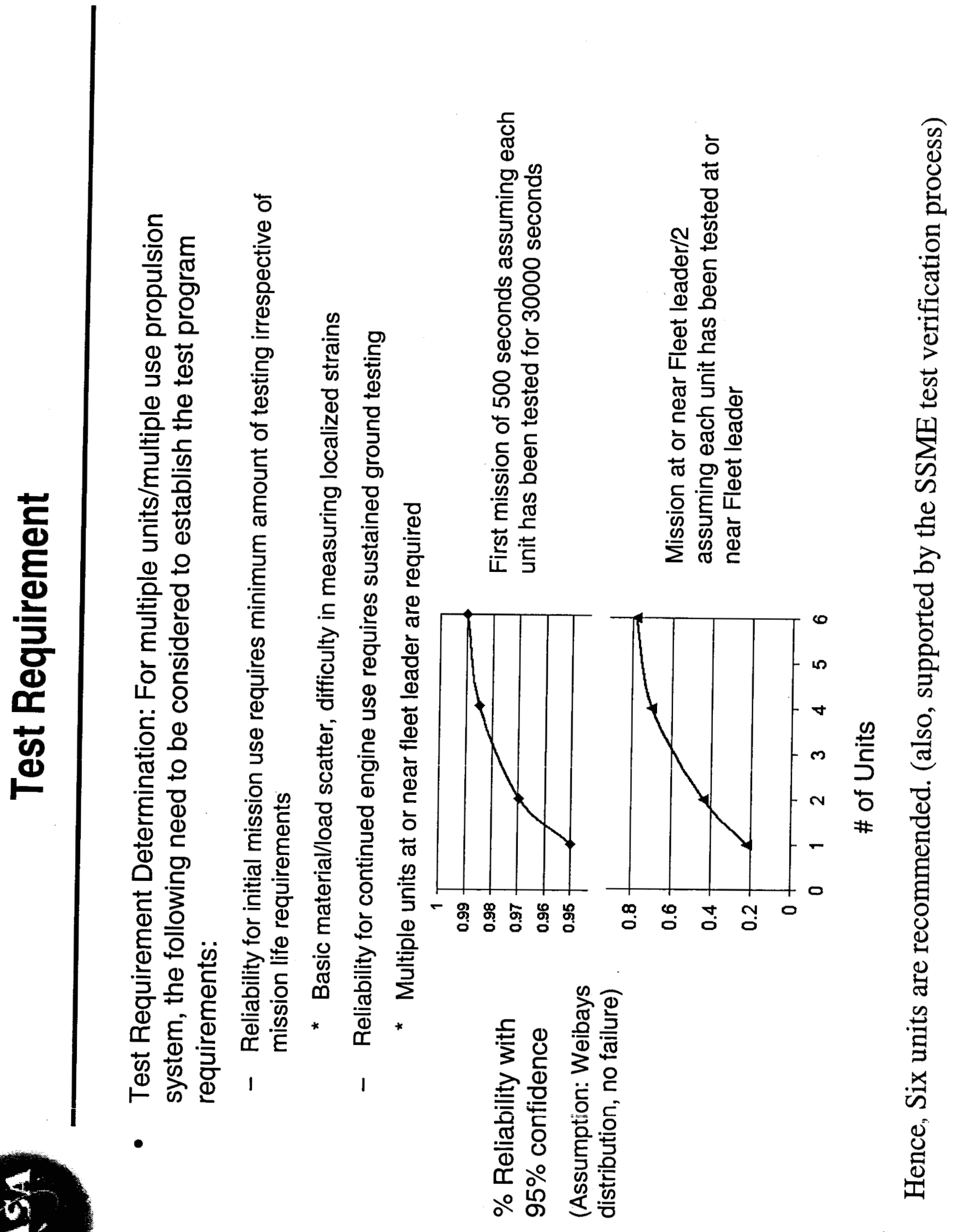



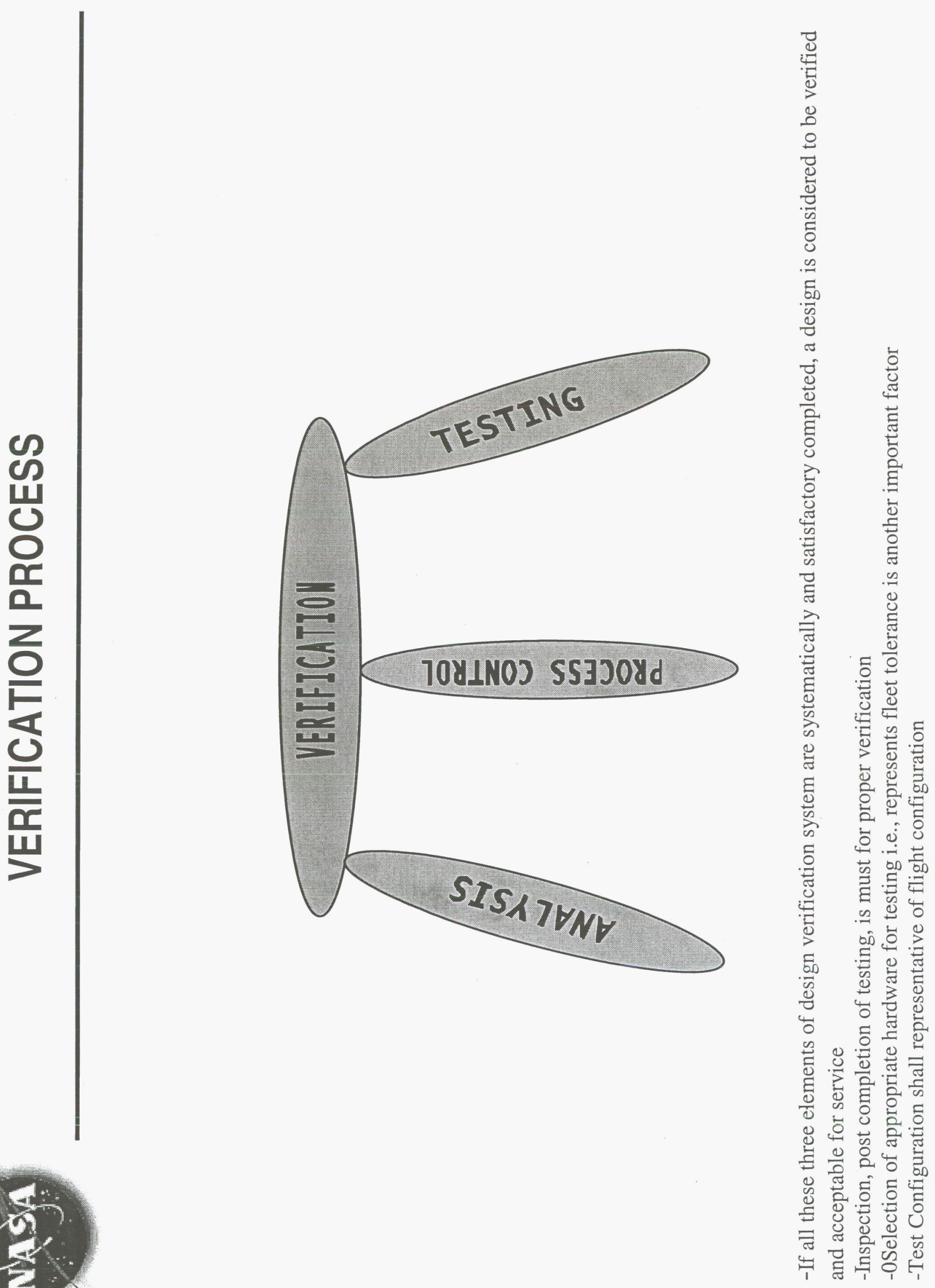

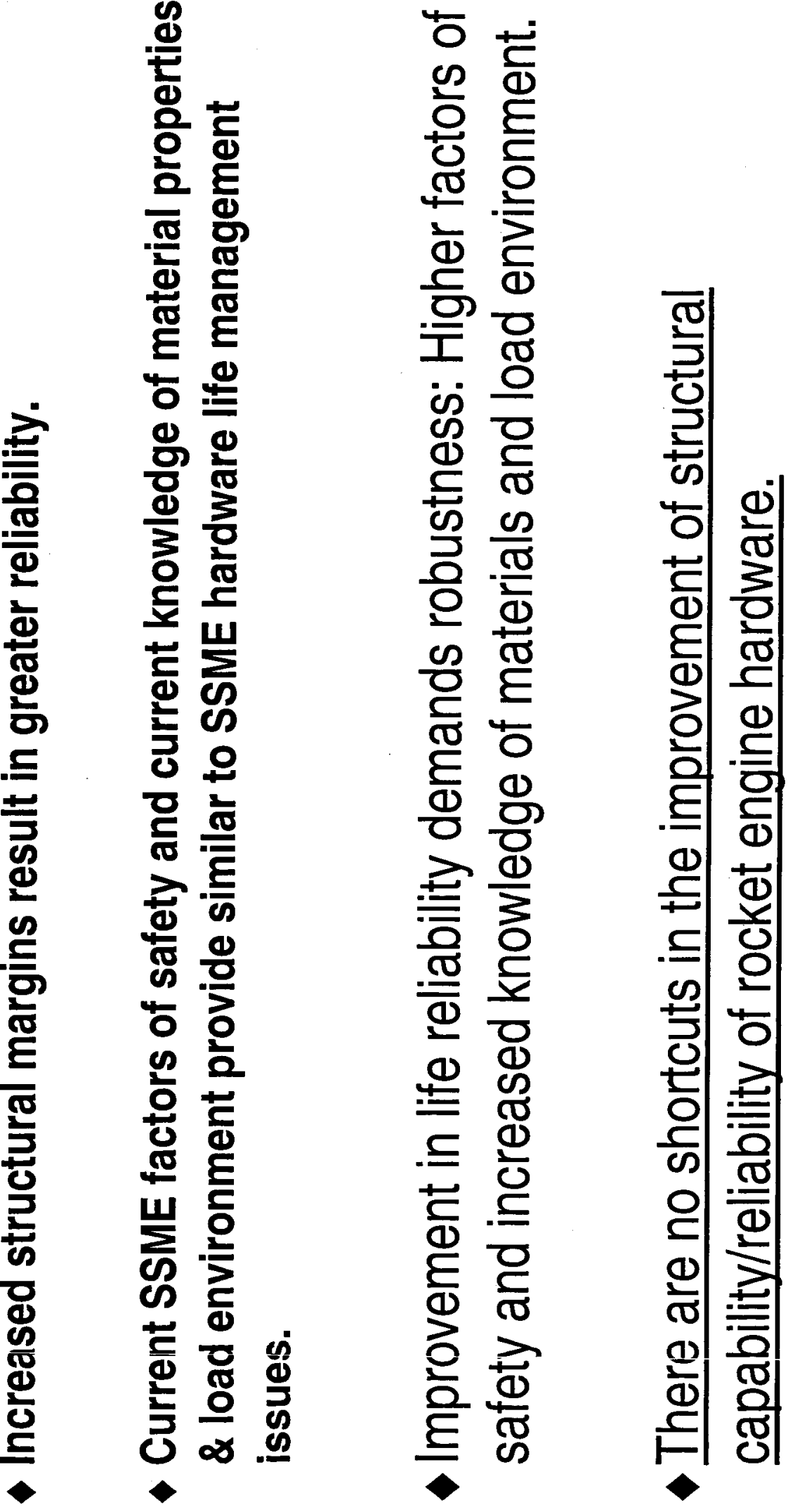


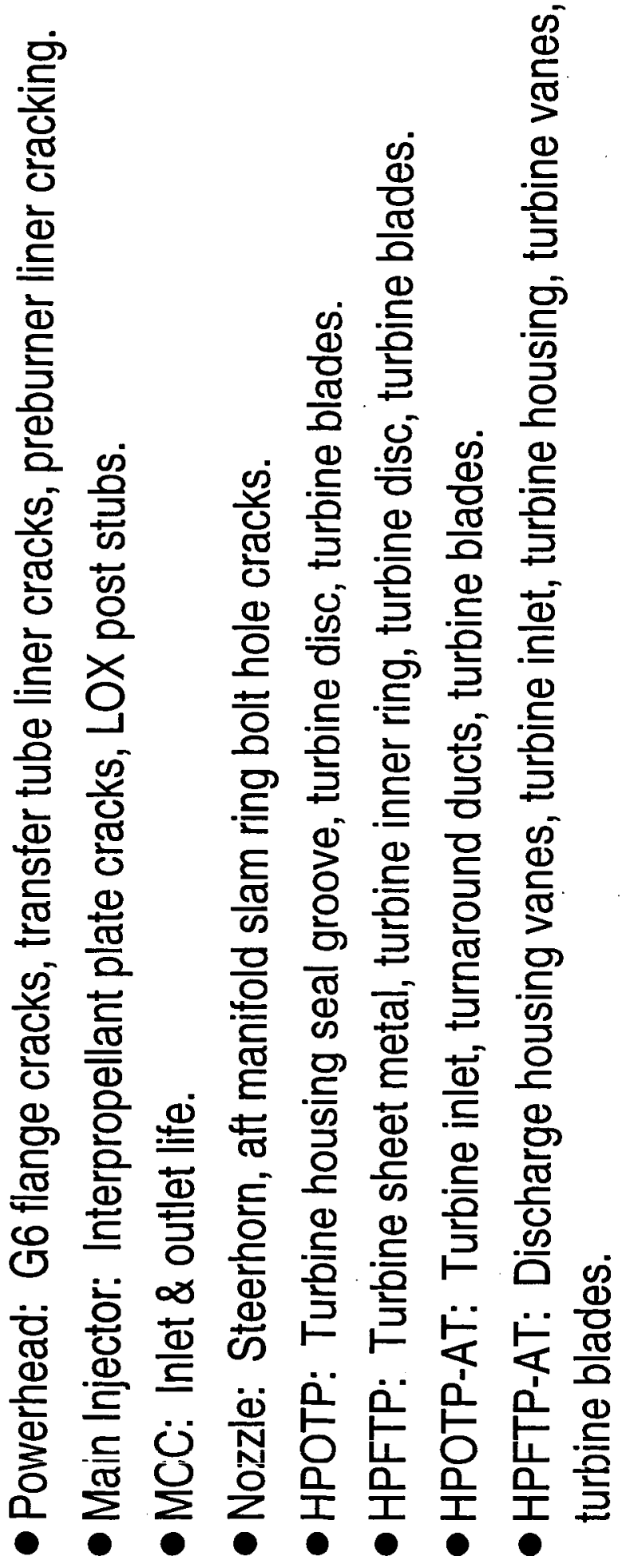




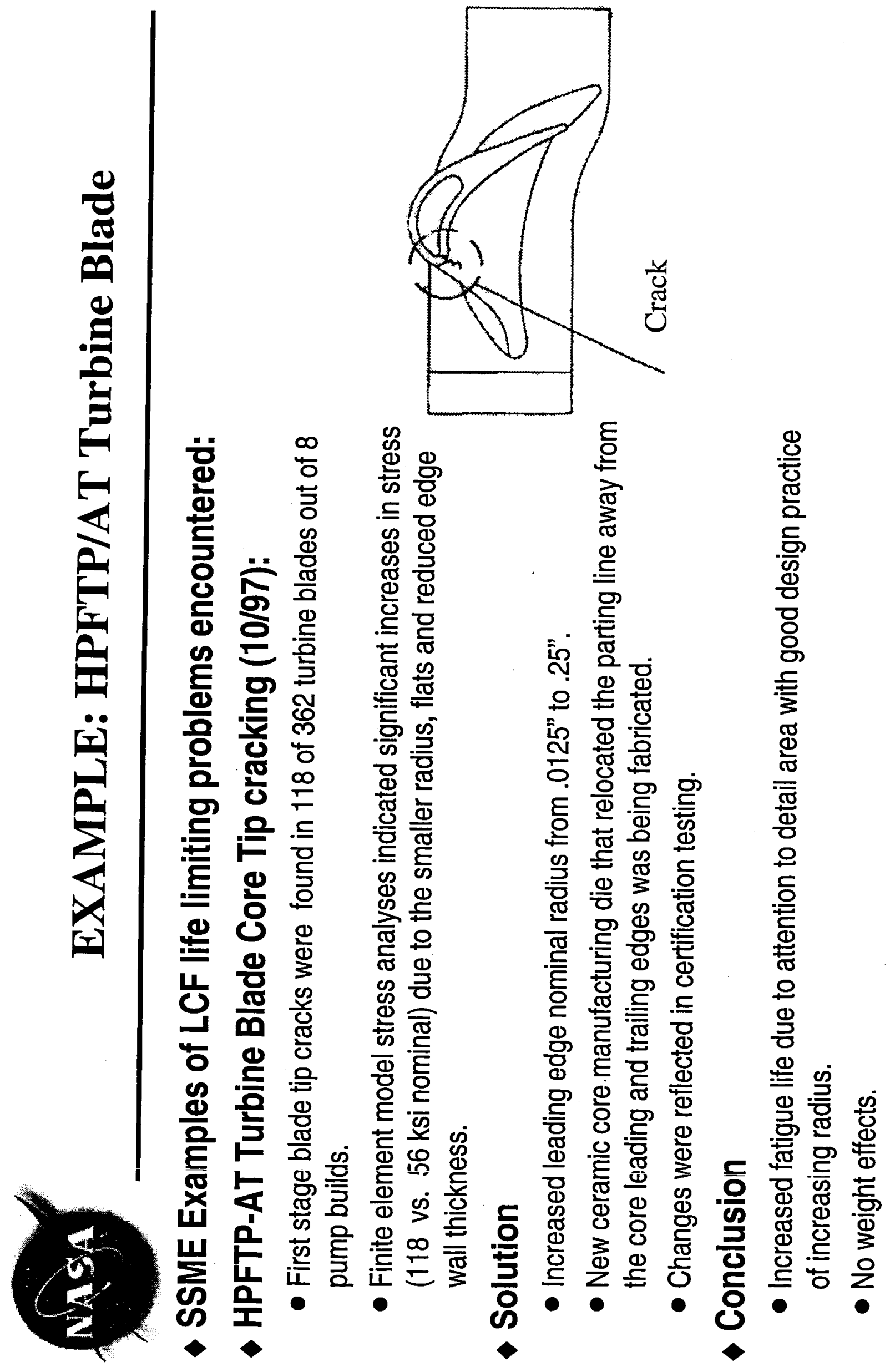




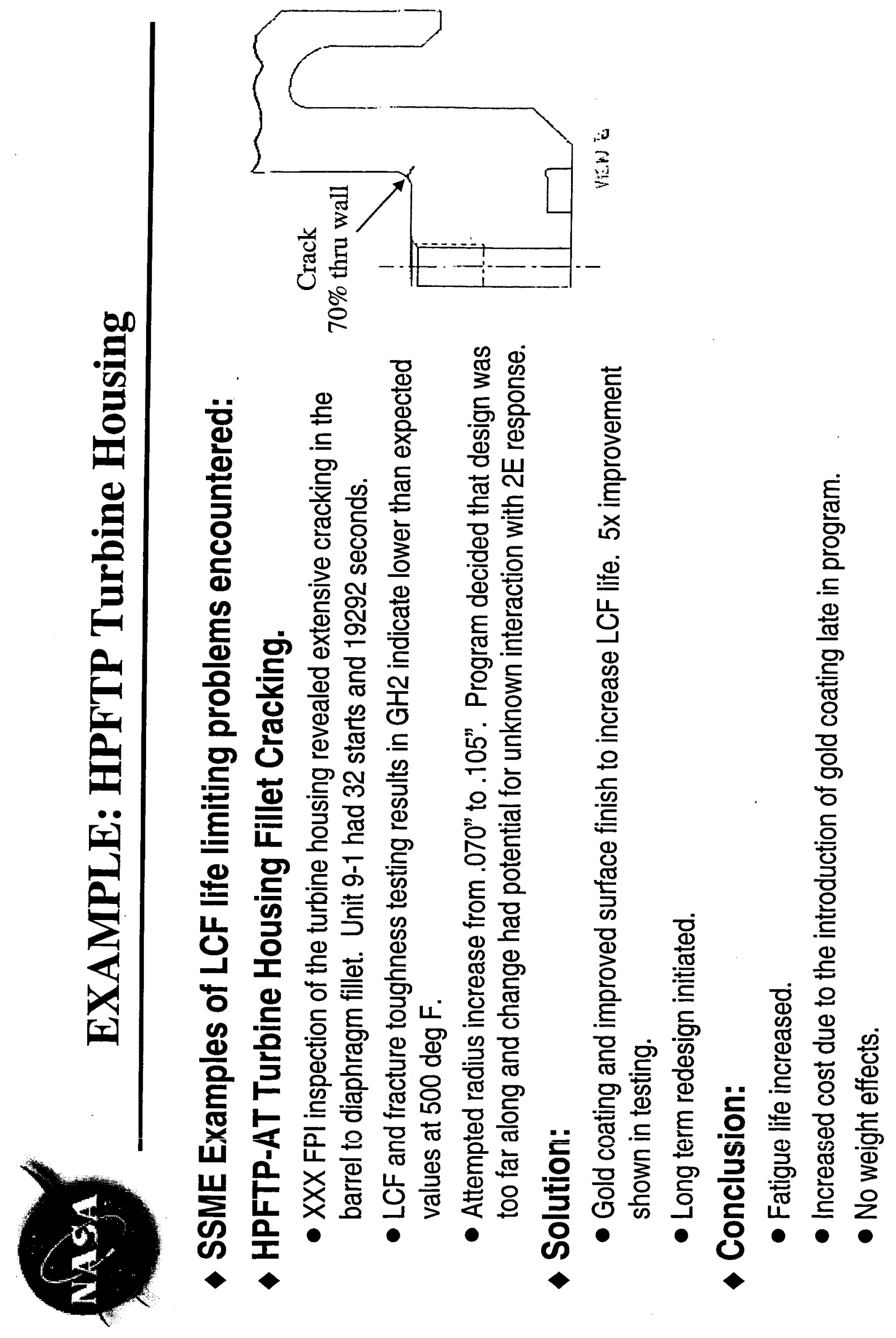




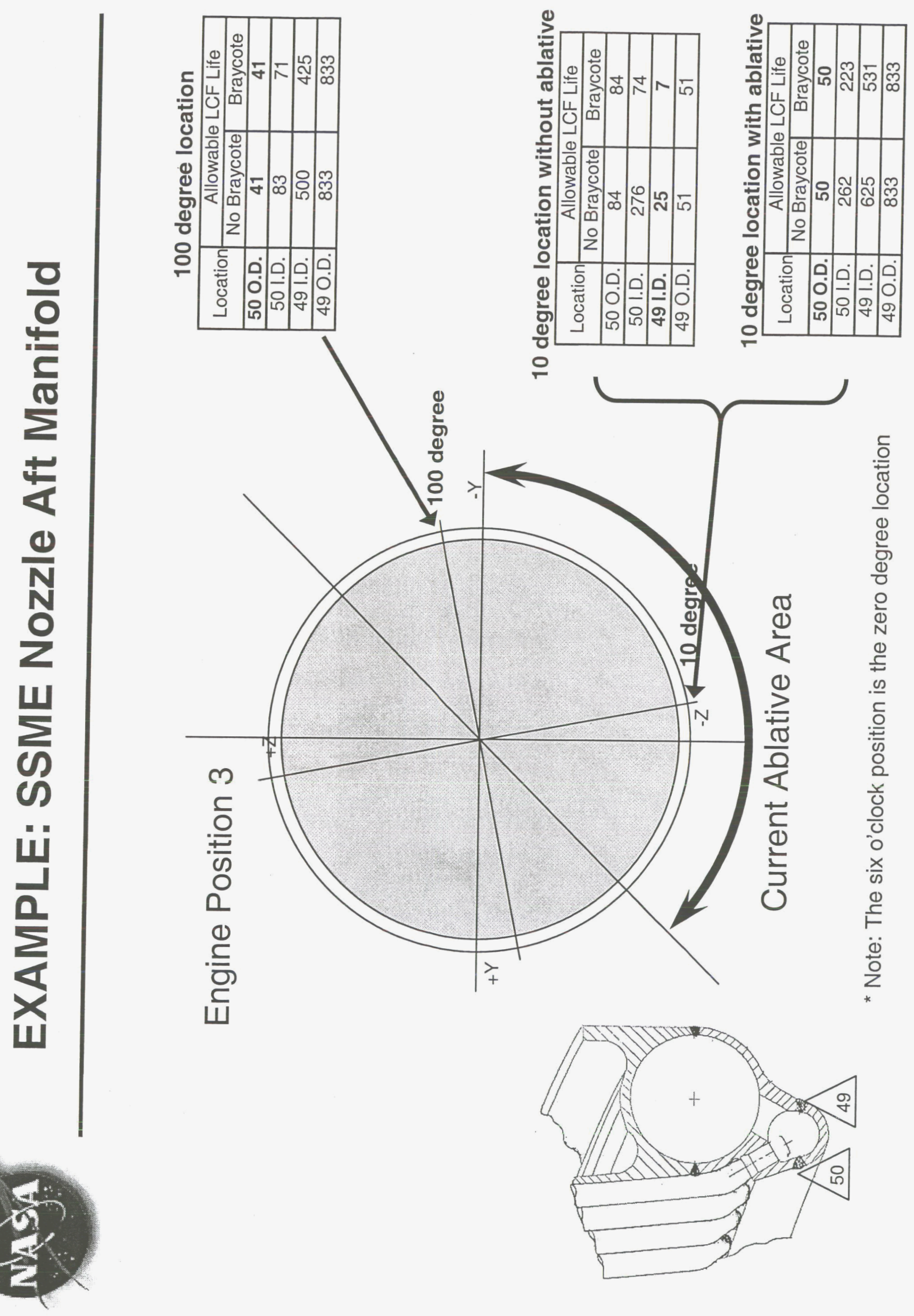




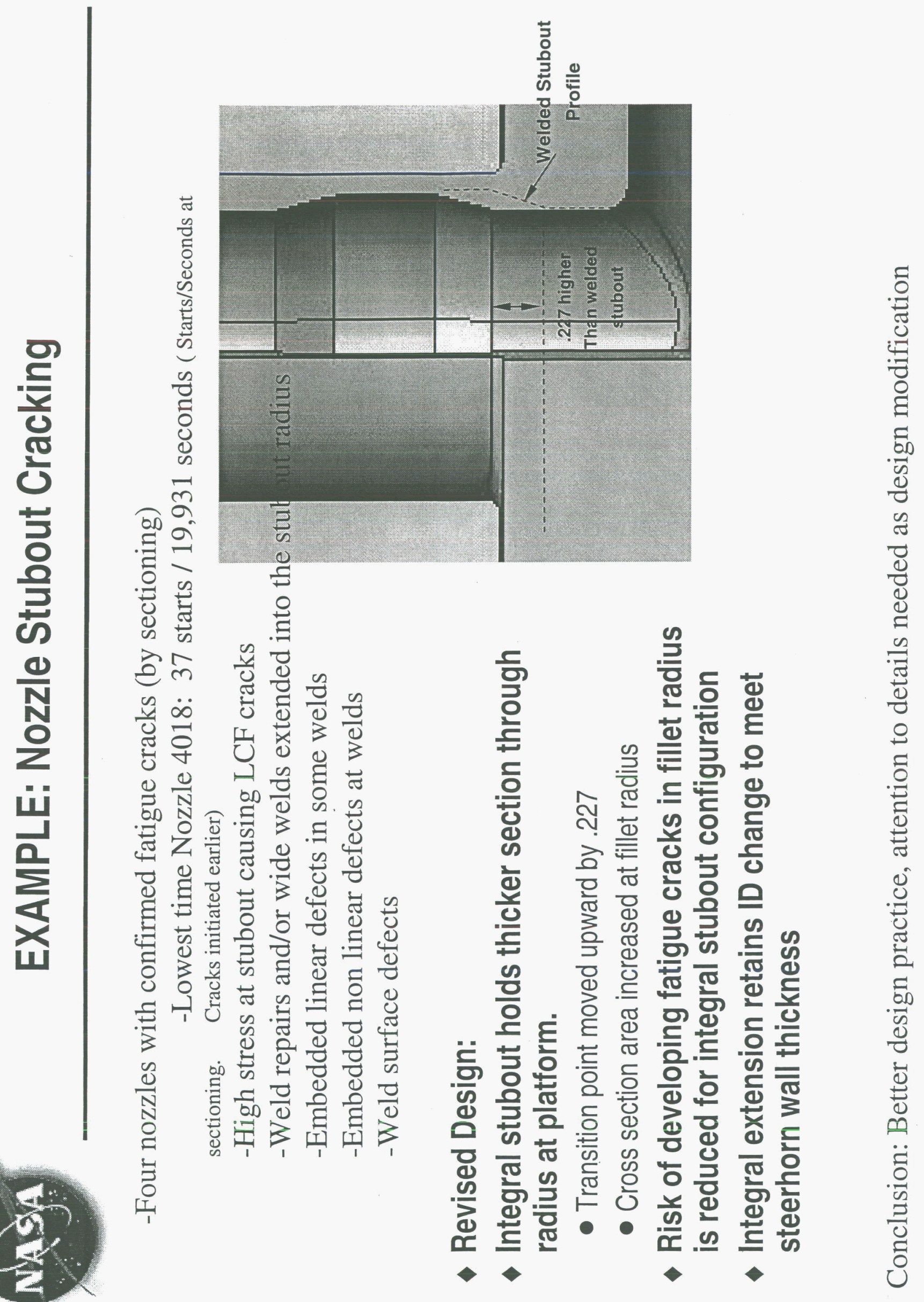

